\title{
Problem-based learning in medical education: one of many learning paradigms
}

\section{The role of problem-based learning should be weighed carefully against that of other models}

n 1978, when problem-based learning (PBL) was introduced in the University of Newcastle medical faculty, ${ }^{1}$ the prevailing educational style in 6-year undergraduate medical programs in Australia was teacher-led learning (TLL), wherein students first acquired core knowledge in basic sciences, which were taught in large class lectures, tutorials and laboratory sessions during the 3 preclinical years of the course. They then progressed to a multilayered, sequential, integrated approach incorporating fundamental clinical skills in history-taking and eliciting and interpreting physical signs, leading to differential diagnoses and patient management. These skills were taught in small tutorial groups at the bedside, in the operating room, in outpatient clinics and in consulting rooms. During the clinical years students were assigned to separate blocks (medicine, surgery, obstetrics and gynaecology, paediatrics and psychiatry) where they were embedded in the daily activities of individual departments. These departments were responsible for designing and delivering separate lecture-based programs which, together with recommended textbooks and printed handouts, provided core information. The students were taught, assessed and examined by each department separately. The integration of basic sciences, pathology and clinical practice was reinforced during the clinical years, but there was little or no cross-disciplinary integration. Thus the learning experience was acquired from vertically structured academic departments and hospital clinical services. Although some attention was given to personal development, communication, medical ethics and the law, it was assumed that these would be largely absorbed from mentors. Anecdotally, the competence of Australian medical graduates from this system was well regarded throughout the Englishspeaking world.

In the late 1970s, the medicopolitical environment began to reassess hospital practice and patient care. In particular, questions were raised about whether patients should be treated solely by individual clinicians and their departments rather than in a multidisciplinary manner, and the limited evidence base for many treatments meant that claims of their efficacy were increasingly challenged. There was a push for a holistic approach to patient care and a perception that communication and empathy were lacking. Consequently, hospital organisation was changed from vertical structures to horizontal streaming across disciplines and even across geographical districts. It was assumed that horizontal streaming (for example, neurology linked to neurosurgery; urology and renal medicine) would lead to better patient outcomes. At the same time, three fundamental changes occurred. Funding for universities contracted, models of patient care changed and there was a rapid growth of information technology. These changes, among others, led to medical schools seeking alternative models for teaching and learning in this new environment. It was argued that detailed knowledge of the basic sciences was not essential; instead, there should be greater emphasis on communication, medical ethics, professional development, self-motivated lifelong learning, problem solving and a multidisciplinary approach to illness, wellbeing and patient care. This philosophy led to several changes including a shift from the traditional 6 -year course to 5 years or 4 years, the introduction of graduate medical programs, and the use of PBL as the main vehicle for teaching in some Australian medical schools subsequent to it having been developed and adopted at McMaster University School of Medicine in 1965.

There is no single, accepted definition of PBL, but its doi: 10.5694/mjal3.00060 central concept is that students learn best by working collaboratively on real-world problems. ${ }^{2}$ It seemed to offer several advantages. It encouraged horizontal multidisciplinary integration; it emphasised a discovery mode of self-learning in contrast to rote learning; and it promised the acquisition of knowledge that was titrated against the problem to be solved rather than to the disciplines which had hitherto been thought necessary for students to master. Furthermore, the role of the facilitator in PBL sessions was to direct group learning without having detailed knowledge or vocabulary of the problem to be solved, which led to the introduction of a new breed of non-specialist facilitator supported by medical education centres rather than by traditional departments and disciplines. Consequently, many clinicians who had hitherto been willing to devote their time to clinical teaching and mentoring now found themselves disconnected and disenfranchised. Expert bedside clinical teaching suffered, and student contact with practising physicians was diluted. Enquirybased learning ${ }^{3}$ and case-based learning, ${ }^{2,4}$ in which knowledgeable instructors promote active engagement in the process of enquiry, and where clinical problems are raised and students attempt to solve them during the session, are put forward as alternatives to PBL, but these have not been adopted widely.

The impact of PBL was particularly detrimental to dissection-based courses in anatomy, which rapidly fell into decline despite opposition, ${ }^{5}$ both in Australia and worldwide. ${ }^{6-8}$ For example, at the University of Sydney, anatomy teaching fell from 253 hours in the first 2 years of the old undergraduate course in 1996 to 50.5 hours in the new graduate teaching program in $1997 .{ }^{9}$ As a result, students now question whether their knowledge of gross 
anatomy is adequate for safe medical practice and argue for a return to cadaver dissection. ${ }^{10}$ This has led not only to a proliferation of student requests for optional extracurricular courses in anatomy to provide cliniciansupervised dissection, ${ }^{11,12}$ but also to acknowledgement that there is a need for an overall improvement in anatomy teaching for the betterment of future surgical training. ${ }^{13}$ Arguably this deficiency would be best served by establishing a national core curriculum. ${ }^{14}$ The appropriateness of PBL in anatomy teaching continues to be examined in Australia ${ }^{15}$ and in other countries. ${ }^{16-18}$ PBL has also had a detrimental impact on the delivery of meaningful programs in surgery. The surgical themes of PBL cases were minimised, and student exposure to surgical teaching suffered. Increasingly, students have found it necessary to establish their own societies in order to promote surgical teaching, course content and career pathways. ${ }^{19}$

PBL has spread worldwide over the past four decades, and we are now in a position to consider its effectiveness in comparison with TLL. Two early major reviews of the effectiveness of PBL were cautious but indicated a tendency for PBL to achieve more positive outcomes than TLL on a variety of dimensions of learning. ${ }^{20,21}$ However, it was also noted that it is very difficult to conduct highquality generalisable, comparative research on PBL because of variations in definitions and implementations of PBL, conceptual problems in choosing and defining outcome variables, and the difficulty of designing studies that circumvent a wide range of methodological problems such as confounding, sampling bias and lack of blinding. ${ }^{21}$ From 1994 to 2008, several evaluative studies were published. ${ }^{22}$ Two very recent reviews, spanning more than two decades of research, reach very similar conclusions: "Twenty-two years of research shows that PBL does not impact knowledge acquisition; evidence for other outcomes does not provide unequivocal support for enhanced learning" 22 and “...PBL has a number of positive effects in key areas of student education but there is limited high quality evidence to prove its superiority over the teacher led education". ${ }^{23}$ Indeed, it is striking that, although PBL was introduced contemporaneously with the emergence of evidencebased medicine, to date, there is very little high-quality evidence for its effectiveness compared with TLL. Whether or not PBL can develop students' insight into the sciences that underlie medical practice has not been demonstrated, but this could be an interesting focus of future research. ${ }^{16,17}$

Historically, undergraduate medical education has employed a variety of learning paradigms and teaching methods including TLL, PBL, case-based learning, large group lectures, small group tutorials, bedside teaching, dissection- and prosection-based learning, computerassisted interactive learning and human patient simulations among others. None of these is universally accepted as optimal in all circumstances, and all can contribute to effective and efficient education of future health care professionals.

Competing interests: No relevant disclosures.

Provenance: Not commissioned; externally peer reviewed.

1 Prideaux D. Medical education in Australia: much has changed but what remains? Med Teach 2009; 31: 96-100.

2 Wittert GA, Nelson AJ. Medical education: revolution, devolution and evolution in curriculum philosophy and design. Med J Aust 2009; 191: 35-37.
PBL has also had a detrimental impact on the delivery of meaningful programs in surgery
3 Wood WB. Inquiry-based undergraduate teaching in the life sciences at large research universities: a perspective on the Boyer Commission Report. Cell Biol Educ 2003; 2: 112-116.

4 Thistlethwaite JE, Davies D, Ekeocha S, et al. The effectiveness of casebased learning in health professional education. A BEME systematic review: BEME guide No. 23. Med Teach 2012; 34: e421-e444.

5 Fahrer M. Art macabre: is anatomy necessary? ANZ J Surg 2001; 71: 333-334.

6 Craig S, Tait N, Boers D, McAndrew D. Review of anatomy education in Australian and New Zealand medical schools. ANZ J Surg 2010; 80: 212-216.

7 Nicholson $\mathrm{H}$. The future of anatomy: where do we go from here? ANZ J Surg 2005: 75: 95

8 Turney BW. Anatomy in a modern medical curriculum. Ann R Coll Surg Engl 2007; 89: 104-107.

9 Ramsey-Stewart G, Burgess AW, Hill DA. Back to the future: teaching anatomy by whole-body dissection. Med J Aust 2010; 193: 668-671.

10 Insull PJ, Kejriwal R, Blyth P. Surgical inclination and anatomy teaching at the University of Auckland. ANZ J Surg 2006; 76: 1056-1059.

11 Roberts MJ, Manoharan B, Vonau, et al. Delivering supplemental anatomy education: the University of Queensland model. Med J Aust 2011; 195: 449.

12 Hattam AT, Diaz CM. Medical student-initiated anatomy education: an extra-curricular experience at a regional medical school. Med J Aust 2012; 197: 218.

13 Herle P, Saxena A. Contemporary teaching of anatomy in Australian medical schools: are we doing enough? ANZ J Surg 2011; 81: 662-663.

14 Chapuis P, Fahrer M, Eizenberg $\mathrm{N}$, et al. Should there be a national core curriculum for anatomy? ANZ J Surg 2010; 80: 475-477.

15 Azer SA, Eizenberg N. Do we need dissection in an integrated problembased learning medical course? Perceptions of first- and second-year students. Surg Radiol Anat 2007; 29: 173-180.

16 Pabst R. Anatomy curriculum for medical students: what can be learned for future curricula from evaluations and questionnaires completed by students, anatomists and clinicians in different countries? Ann Anat 2009; 191: 541-546.

17 Bergman EM, van der Vleuten CP, Scherpbier AJ. Why don't they know enough about anatomy? A narrative review. Med Teach 2011; 33: 403-409.

18 Bergman EM, de Bruin AB, Herrler A, et al. Students' perceptions of anatomy across the undergraduate problem-based learning medical curriculum: a phenomenographical study. BMC Med Educ 2013; 13: 152.

19 Cundy T, Chanisheff D, Devitt PG, Beilby J. Surgical interest societies for medical students. ANZ J Surg 2009; 79: 406.

20 Albanese MA, Mitchell S. Problem-based learning: a review of literature on its outcomes and implementation issues. Acad Med 1993; 68: 52-81.

21 Vernon DT, Blake RL. Does problem-based learning work? A meta-analysis of evaluative research. Acad Med 1993; 68: 550-563.

22 Hartling L, Spooner C, Tjosvold L, Oswald A. Problem-based learning in pre-clinical medical education: 22 years of outcome research. Med Teach 2010; 32: 28-35.

23 Polyzois I, Claffey N, Matheos N. Problem-based learning in academic health education. A systematic literature review. Eur J Dent Educ 2010; 14 : 55-64 